\title{
Drought variations in the eastern part of northwest China over the past two centuries: evidence from tree rings
}

\author{
Keyan Fang ${ }^{1,2}$, Xiaohua Gou ${ }^{1, *}$, Fahu Chen ${ }^{1}$, Meixue Yang ${ }^{3}$, Jinbao Li $^{2}$, Maosheng He $^{4}$, \\ Yong Zhang ${ }^{1}$, Qinghua Tian ${ }^{1}$, Jianfeng Peng ${ }^{1}$ \\ ${ }^{1}$ Center for Arid Environment and Paleoclimate Research (CAEP), MOE Key Laboratory of Western China's Environmental \\ Systems, Lanzhou University, Lanzhou 730000, China \\ ${ }^{2}$ Tree-Ring Laboratory, Lamont-Doherty Earth Observatory, Columbia University, Palisades, New York 10964, USA \\ ${ }^{3}$ Cold and Arid Regions Environmental and Engineering Research Institute, Chinese Academy of Sciences, \\ Lanzhou 730000, China \\ ${ }^{4}$ Institute of Geology and Geophysics, Chinese Academy of Sciences, Beijing 100029, China
}

\begin{abstract}
Drought reconstruction from 1794 to 2003 in the eastern part of NW China was developed by calibrating tree rings of Picea wilsonii on Xinglong Mountain with the Palmer drought severity index (PDSI). The reconstruction explains $40 \%$ of the actual PDSI variance during the period from 1951 to 2003. The most significant drought period over the reconstructed time span occurred during the 1920s to 1930s. The drought reconstructions show a climate transition in 1921 on a decadal scale and significant cyclic patterns that were identified in intervals of 10.5, 7.9-8.3, 3.5, 3.0-3.2, 2.7-2.8 and $\sim 2$ yr. This reconstruction is representative of regional drought patterns in eastern NW China and demonstrates that they are different from patterns in western NW China.
\end{abstract}

KEY WORDS: Dendrochronology $\cdot$ PDSI $\cdot$ Asian monsoon · Northwest China

\section{INTRODUCTION}

Droughts and floods are among the world's costliest natural disasters and have great impacts on regional natural and socioeconomic systems (Wilhite 2000). For example, local historical archives in North China (Shanxi Committee of Natural Disasters Annals 2002) recorded a megadrought during the 1920s to $1930 \mathrm{~s}$ that resulted in the starvation of at least 4 million people. Studies have indicated that such severe dry and wet weather events will increase due to global warming, and the drought patterns and their temporal variability will be distinct in different regions (Qian \& Qin 2008). The above findings highlight the need to study drought variations in different regions. In NW China, moisture patterns since the 1980s have been classified into 3 types (Shi et al. 2007): a distinct pattern of change from dry to wet in western NW China, a continually drier pattern in eastern NW China, and a transitional zone between these areas. Many studies have been conducted to investigate the trend of increased moisture in western NW China and whether such a trend could be spreading over the entire area of NW China (e.g. Li et al. 2006, Shi et al. 2007).

The meteorological records in NW China seldom extend back to a time before the 1950s, which has limited the drought studies in this area (Li et al. 2007). However, tree rings have been widely used for drought reconstructions (e.g. Cook et al. 1999, Garfin et al. 2005, Li et al. 2006, 2007, Tian et al. 2007). The Palmer drought severity index (PDSI) was created by Palmer (1965) with the intent to quantitatively determine the accumulated deficit in local mean moisture conditions, allowing comparisons of drought severities across regions and time. Dai et al. (2004) developed a PDSI dataset to encompass the world, with a $2.5 \times 2.5^{\circ}$ gridding system following the Palmer (1965) methodology. As one of the most widely used meteorological drought indices in the USA (Cook et al. 1999), the PDSI has also been proved to be useful for drought studies in 


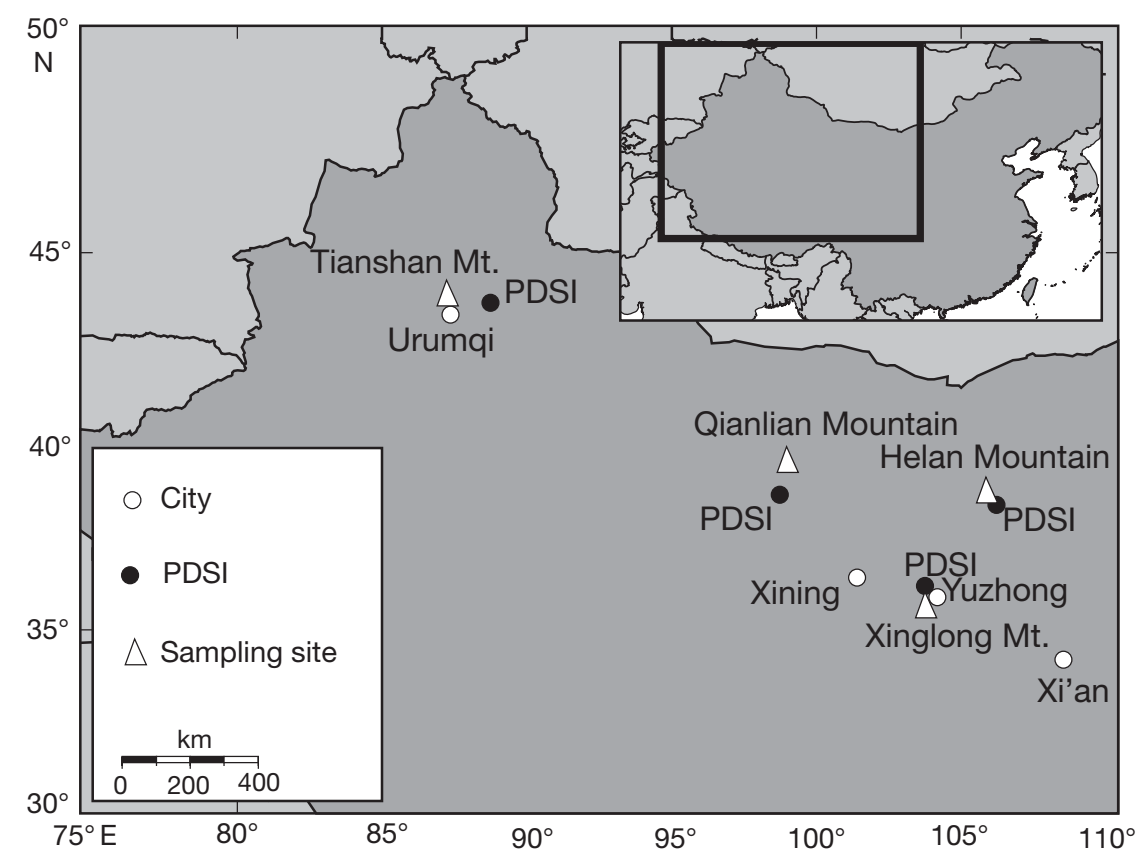

Fig. 1. Locations of sampling site (Xinglong Mountain), Palmer drought severity index (PDSI) grid point and meteorological stations (city sites) in NW China. Other available PDSI reconstructions in NW China, their associated sampling sites and meteorological stations are also shown

China (e.g. Li et al. 2006, 2007, Tian et al. 2007). In NW China, although many dendroclimatological reconstructions have been conducted (e.g. Garfin et al. 2005, Gou et al. 2005, 2007, Liu et al. 2005, Shao et al. 2005, Li et al. 2006, 2007, Tian et al. 2007), only a few of these studies include reconstructions of the PDSI (Fig. 1; Li et al. 2006, 2007, Tian et al. 2007). This is partly because there are only sparse 'green islands' in NW China, where old forests can be found, largely due to the dry climate and long history of human activities. In the current study, we present a drought (PDSI) reconstruction for Xinglong Mountain (hereafter XM) in the eastern part of NW China and discuss the underlying drought regimes. The aims of the present study were to: (1) reconstruct the nearest PDSI grid with the use of tree rings from $\mathrm{XM}_{i}(2)$ analyze the variability of the reconstructed PDSI grid and explore its relationship to regional moisture patterns.

\section{MATERIALS AND METHODS}

\subsection{Study region and tree-ring data}

Tree rings were collected from Picea wilsonii on XM $\left(35^{\circ} 38^{\prime}\right.$ to $35^{\circ} 58^{\prime} \mathrm{N}, 103^{\circ} 50^{\prime}$ to $\left.104^{\circ} 10^{\prime} \mathrm{E}\right)$ in the eastern part of NW China (Fig. 1). This region is characterized as having a semi-arid, continental climate, with peaks in temperature and precipitation in July and August, respectively (Fig. 2). The annual average temperature and total annual precipitation based on data from the nearest meteorological station (Yuzhong Station; Fig. 2) are $6.7^{\circ} \mathrm{C}$ and $390 \mathrm{~mm}$, respectively. The study location is considered a transitional area between the arid region and the humid region based on an annual precipitation of around 400 mm (Chinese Committee of Agricultural Resources Planning 1984). Standard dendrochronological methods (Fritts 1976) were employed to develop a robust ring-width chronology. Two cores per tree of the locally dominant tree species $P$. wilsonii were extracted at breast height. This species is distributed from an altitude of $1900 \mathrm{~m}$ up to the mountain peak at $2900 \mathrm{~m}$, as no natural tree limit for $P$. wilsonii was observed on XM. From 57 trees, 93 cores were sampled along an altitudinal gradient ranging from 2370 to $2570 \mathrm{~m}$ (Table 1).

Following the methodology of Stokes \& Smiley (1968), all cores were mounted, air dried and sanded to produce a polished transverse surface for visual crossdating. Samples were crossdated using skeleton plots, and the subsequently measured series were checked by the program COFECHA (Holmes 1983) for quality control of visual crossdating. In order to preserve lowfrequency climate signals while removing the agerelated growth trends, we adopted conservative functions for the most part, such as negative exponential functions or the linear function of any slope, to detrend the tree-ring widths. Also, a Friedman super-smoother

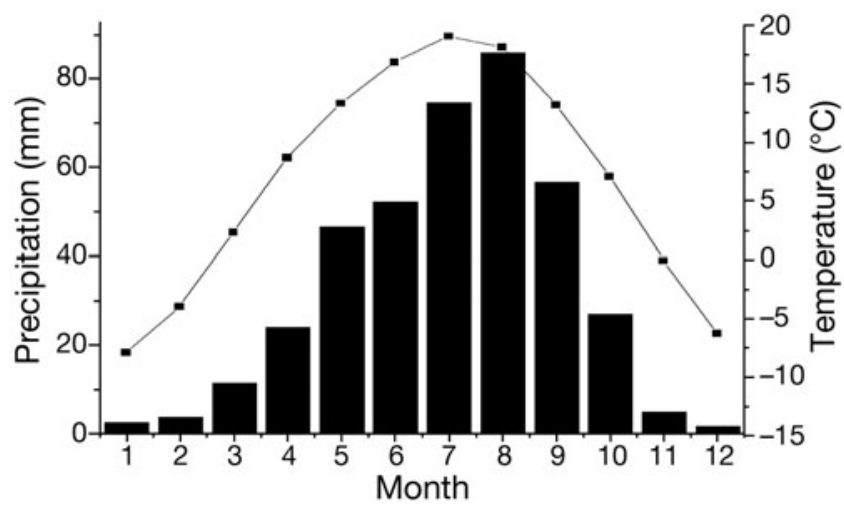

Fig. 2. Monthly mean temperatures (line with squares) and monthly total precipitation (bars) for 1954 to 2003 based on available records from the Yuzhong meteorological station 
Table 1. General information on the composite chronology site, the closest meteorological station (Yuzhong) and the nearest Palmer draught severity index (PDSI) grid point

\begin{tabular}{|lccccc|}
\hline Site & Latitude & Longitude & $\begin{array}{c}\text { Elevation } \\
\text { (m) }\end{array}$ & $\begin{array}{c}\text { Time interval } \\
\text { (reliable period) }\end{array}$ & $\begin{array}{c}\text { Cores/ } \\
\text { Trees }\end{array}$ \\
\hline $\begin{array}{l}\text { Composite } \\
\text { chronology }\end{array}$ & $35^{\circ} 40^{\prime} \mathrm{N}$ & $104^{\circ} 02^{\prime} \mathrm{E}$ & $2370-2570$ & $1794-2003$ & $93 / 57$ \\
$\begin{array}{l}\text { Meteorological } \\
\text { station }\end{array}$ & $35^{\circ} 52^{\prime} \mathrm{N}$ & $104^{\circ} 09^{\prime} \mathrm{E}$ & 1917 & $1954-2003$ & \\
$\begin{array}{l}\text { PDSI grid point } \\
\text { PS }\end{array}$ & $36^{\circ} 15^{\prime} \mathrm{N}$ & $103^{\circ} 45^{\prime} \mathrm{E}$ & & $1933-2003$ & \\
& & & & $(1951-2003)$ & \\
\hline
\end{tabular}

with alpha 7, which is helpful in preserving lowfrequency signals (E. R. Cook pers. comm.), was also employed to detrend some samples with anomalous growth release and suppression. The first principal component (PC) over the interval from 1850 to 1995 accounts for $97 \%$ of the total variance, demonstrating a common pattern among these tree-ring series. Thus, all the highly correlated series were merged into a single robust chronology (Table 1) by using the program ARSTAN (Cook 1985). With respect to the replication decline in the early portion of the chronology, the subsample signal strength (Wigley et al. 1984) was employed to evaluate the reliable chronology with an arbitrary threshold value of 0.8 . The reliable composite chronology ranged from 1794 to 2003 (Fig. 3).
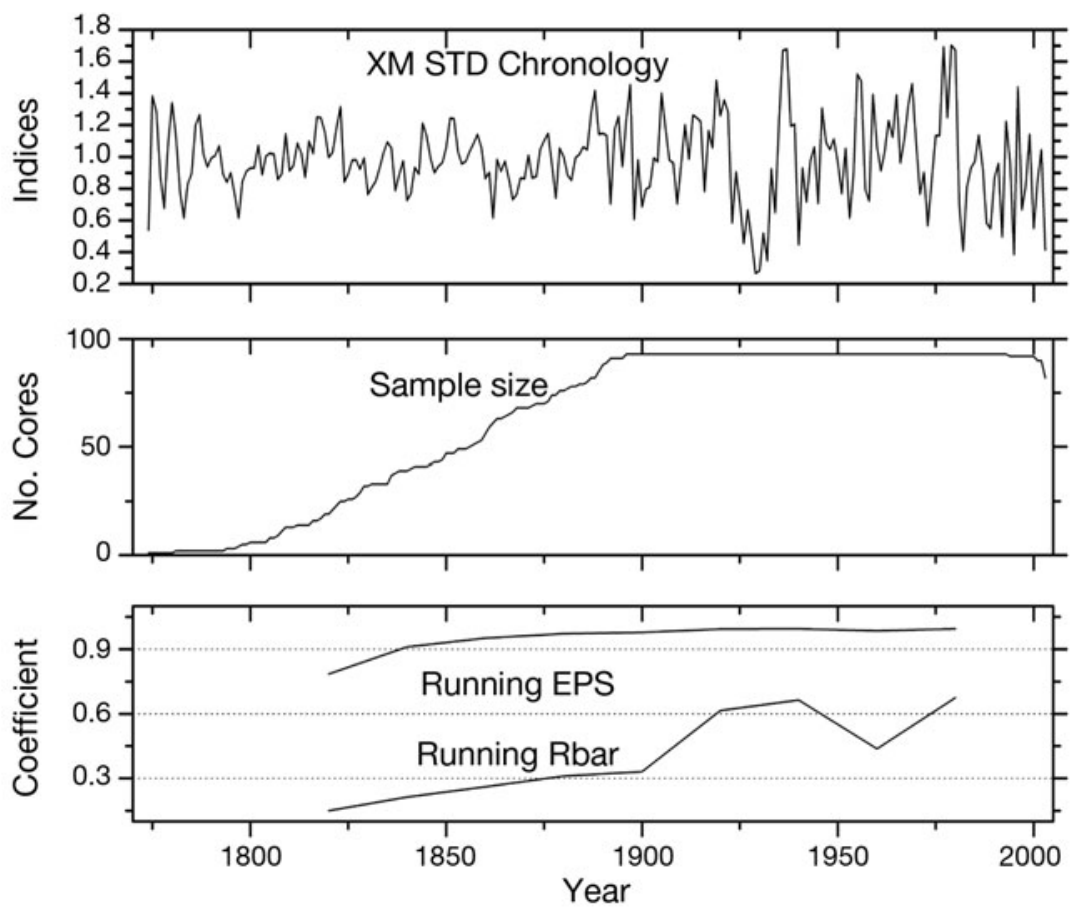

Fig. 3. Standard chronology of Xinglong Mountain (XM), sample size, running expressed population signal (EPS), and Rbar statistics

\subsection{Dendroclimatic methods}

Climate-growth relationships were analyzed by correlating the ring-width indices with meteorological records and the PDSI data. The meteorological data were obtained from the closest meteorological station, Yuzhong Station, for the period from 1954 to 2003 (Fig. 2). The PDSI data from the nearest Dai PDSI grid point covered the period from 1933 to 2003 (Table 1; Dai et al. 2004). Most of the meteorological records in the study region are available for the period after 1951. Therefore, ring-widths were calibrated with the PDSI data during the reliable period from 1951 to 2003. The reconstruction model validation was tested through a split-sample procedure (Meko \& Graybill 1995). As shown in Table 2, the full period was divided into 2 subperiods, 1951 to 1972 and 1973 to 2003; the calibration model was then developed from one subperiod and verified against the remaining data from the other subperiod. Subsequently, the reconstruction model was calibrated with the full period PDSI from 1951 to 2003. A coefficient of efficiency (CE) or reduction of error (RE) $>0$ indicates good model fit, and significant values of $\mathrm{r}, \mathrm{r}^{2}$ and $t$ are also good indicators of an appropriate model (Cook et al. 1999). The drought reconstructions were processed by the MannKendall (Mann 1945) and multi-taper (Mann \& Lee 1996) methods for jump examination and spectral analysis, respectively.

\section{RESULTS}

\subsection{Climate-growth relationships}

As shown in Fig. 3, a robust chronology was developed from 1794 to 2003 based on a subsample strength signal (SSS, Wigley et al. 1984) value of $>0.8$. The high running expressed population signal (EPS) and running Rbar indicate good common signals for segments (Wigley et al. 1984; Fig. 3). Due to the strong biological lag effect, as indicated by the high first-order autoregression value of 0.509 , climategrowth analyses were undertaken from July of the previous year to December. As shown in Fig. 4a, significant correlations (at 0.05 level) with temperatures were found in July of 
Table 2. Statistical results of a sample split calibration verification procedure. All values listed are significant $(\mathrm{p}<0.05)$. $t$ : $t$ statistic; RE: reduction error; CE: coefficient efficiency

\begin{tabular}{|c|c|c|c|c|c|c|c|c|}
\hline \multirow[b]{2}{*}{ Period } & \multicolumn{2}{|c|}{ Calibration - } & \multirow[b]{2}{*}{$t$} & \multirow[b]{2}{*}{ Period } & \multicolumn{2}{|c|}{ Verification } & \multirow[b]{2}{*}{$\mathrm{RE}$} & \multirow[b]{2}{*}{$\mathrm{CE}$} \\
\hline & $\mathrm{r}$ & $\mathrm{R}^{2}$ & & & $\mathrm{r}$ & $t$ & & \\
\hline 1951-1972 & 0.53 & 0.28 & 2.59 & $1975-2003$ & 0.63 & 1.72 & 0.41 & 0.06 \\
\hline $1973-2003$ & 0.63 & 0.40 & 4.37 & 1946-1974 & 0.53 & 1.96 & 0.46 & -0.22 \\
\hline 1951-2003 & 0.63 & 0.40 & 5.83 & & & & & \\
\hline
\end{tabular}

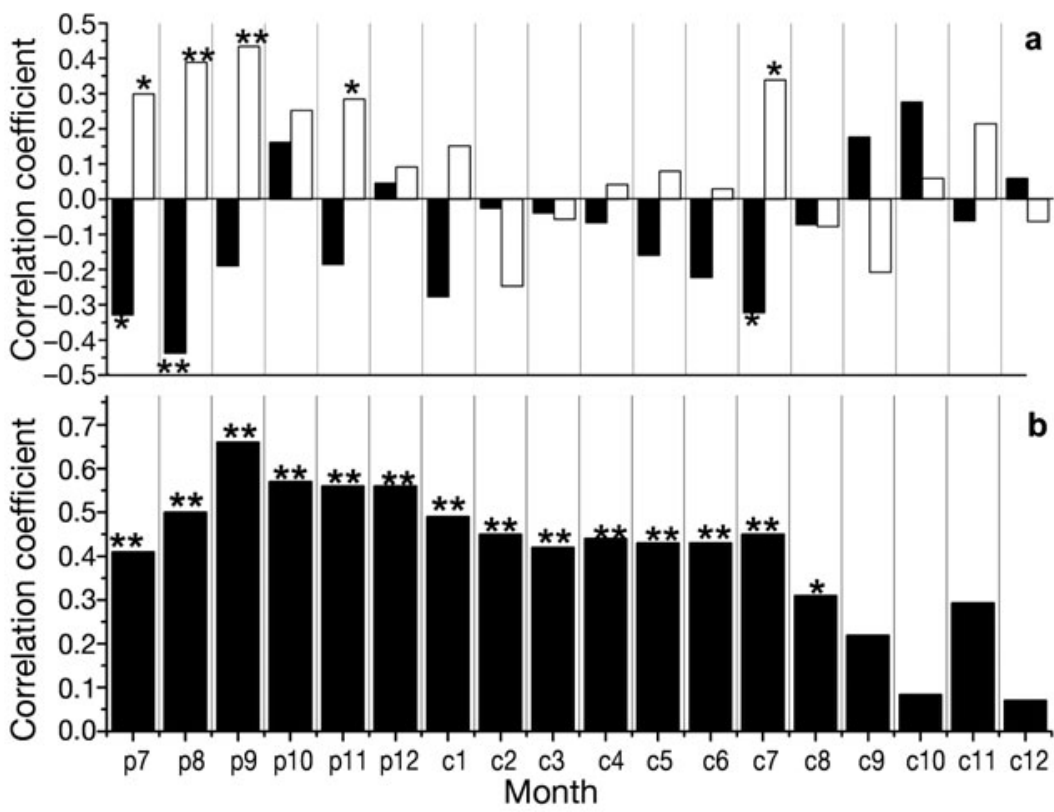

Fig. 4. Comparisons of correlation analysis relating ring-width indices: (a) to temperature (open bars) and precipitation (filled bars) records measured at the closest meteorological station, and (b) to the PDSI grid point during the time interval from 1954 to 2003 . ${ }^{*}$ Correlations exceeding the $95 \%$ confidence limit $(\mathrm{CL}) ;{ }^{* *}$ correlations exceeding the $99 \% \mathrm{CL}$; p: previous year; c: current year with the PDSI data in both the previous and current year (Fig. 4). The most significant correlations between PDSI data and ring-widths were found from August of the previous year to July. Therefore, the ring-width indices were calibrated with annual PDSI from August of the previous year to July.

\subsection{PDSI reconstruction}

With respect to the full-period calibration model, $40 \%$ of the PDSI variance from 1951 to 2003 is explained (Table 2). As shown in Fig. 5, additional visual comparisons between the actual and the reconstructed PDSI values were employed to confirm the validity of the model, indicating a generally good model fit. The linear regression model was applied to reconstruct the regional drought history from 1794 to 2003. A significant ( $p<0.01$ ) jump transition was detected in 1921, at the decadal scale, with the use of the Mann-Kendall method (Mann 1945). Through spectral analyses according to multiple taper methods (MTM), some significant cyclic patterns were identified at intervals of $\sim 10.5$ ( $p<0.05$ ), 7.9 to 8.3 ( $p<0.05$ or higher), 3.5 ( $\mathrm{p}<0.05), 3.0$ to 3.2 (p< $0.05), 2.7$ to $2.8(\mathrm{p}<0.01)$ and $\sim 2 \mathrm{yr}$ (Fig. 6). the previous year $(r=-0.329)$, August of the previous year $(\mathrm{r}=-0.438)$ and July of the current year $(\mathrm{r}=$ -0.323), and significant correlations with precipitation were found in July of the previous year ( $r=0.299)$, August of the previous year $(r=0.389)$, September of the previous year $(r=0.434)$, December of the previous year $(r=0.284)$ and July of the current year $(r=0.339)$. In general, negative correlations with temperature, combined with positive correlations with precipitation, indicate the moisture-stressed growth pattern in dry areas (Fritts 1976). Therefore, we explored the correlations of tree-rings with the PDSI data, which take both temperature and precipitation into account (Palmer 1965). As shown in Fig. 4b, tree rings showed stronger correlations with the PDSI than with meteorological records. Similar to the correlations with temperature and precipitation, tree rings showed high correlations

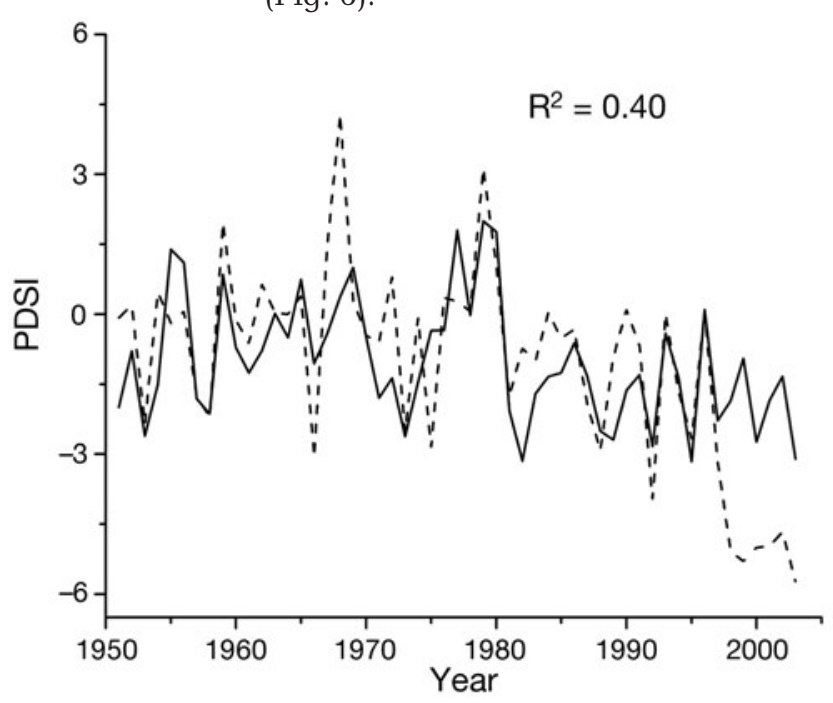

Fig. 5. Reconstructed (solid line) and actual PDSI data (dashed line) during the full calibration period, 1951 to 2003 


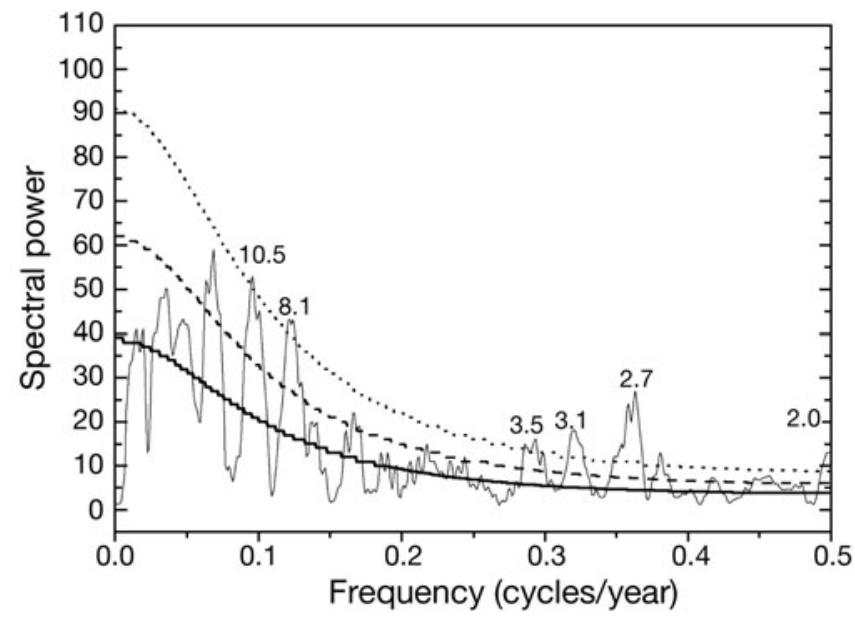

Fig. 6. Spectral density (thin continuous line) according to multiple taper methods of the PDSI reconstruction from 1794 to 2003. Bold, dashed and dotted lines indicate the null hypothesis, $95 \%$ CL and $99 \%$ CL, respectively. Numbers in graph: significant (90\% confidence level) spectral peaks

\section{DISCUSSION}

The high correlations between tree growth and climate factors in the previous year may be due to the fact that winter snow in the non-growing season benefits tree growth early in the growing season. Furthermore, the long life span of the needles may lead to high correlations with the climate records of the previous year (Fritts 1976). Because the reconstruction has a low mean value of -1 , we redefined PDSI values of $-1 \pm 0.5$ to represent normal conditions, and values of less than or equal to -3 or greater than or equal to 1 to represent severe dry or wet conditions (Li et al. 2007). The following discussions are based on the rescaled drought indices. The abnormally dry conditions from 1997 to 2003 (Fig. 5) might have been caused by the significant drying trend and a poor PDSI model fit (Liang et al. 2007). That is, the current PDSI model for this region might have overestimated the effects of the warming trend on the local moisture conditions since 1997, resulting in abnormally dry PDSI values. As shown in Table 2, CE values were abnormally low, especially during the verification period from 1973 to 2003, while the values of RE were much higher than zero. This may have resulted from the mismatches between the actual and estimated data since 1993 (Fig. 5). According to the definitions of $\mathrm{RE}$ and $\mathrm{CE}$
(Fritts 1976, Cook et al. 1999), such mismatches could have resulted in the extraordinarily low and high values of the denominators of CE and RE, especially for the subperiod from 1973 to 2003, which, in turn, led to the abnormally low CE and high RE values.

Spectral peaks of $\sim 2$ yr may indicate a connection between regional drought variability and tropical biennial oscillation (Meehl 1987), and periods of about 10.5 yr might be related to solar effects (Fritts 1976). Periods of $\sim 2,2.7$ to $2.8,3.0$ to 3.2 and $\sim 3.5$ yr fall within the bandwidth of ENSO variability (Allan et al. 1996), and thus may be related to ENSO activities, as documented by meteorological studies in North China (May \& Bengston 1998, Lu 2005). Similar ENSO-related cycles have also been determined in nearby regions in NW China (e.g. Yang et al. 2000, Li et al. 2006, 2007). This might suggest a connection between local droughts and large-scale drought patterns, and possible teleconnections with large-scale moisture circulations. The abrupt drought jump in 1921 detected by the above tests may indicate the start of the 1922 to 1934 megadroughts (Fig. 7). The same abrupt climate jump in 1921 at the sampling site is consistent with the regional climate patterns in North China (Fu \& Wang 1991), indicating that local droughts may be representative of large-scale moisture patterns.

Previous studies based on meteorological records have classified western and eastern NW China into 2 different climatic regions (Shi et al. 2007, Qian \& Qin
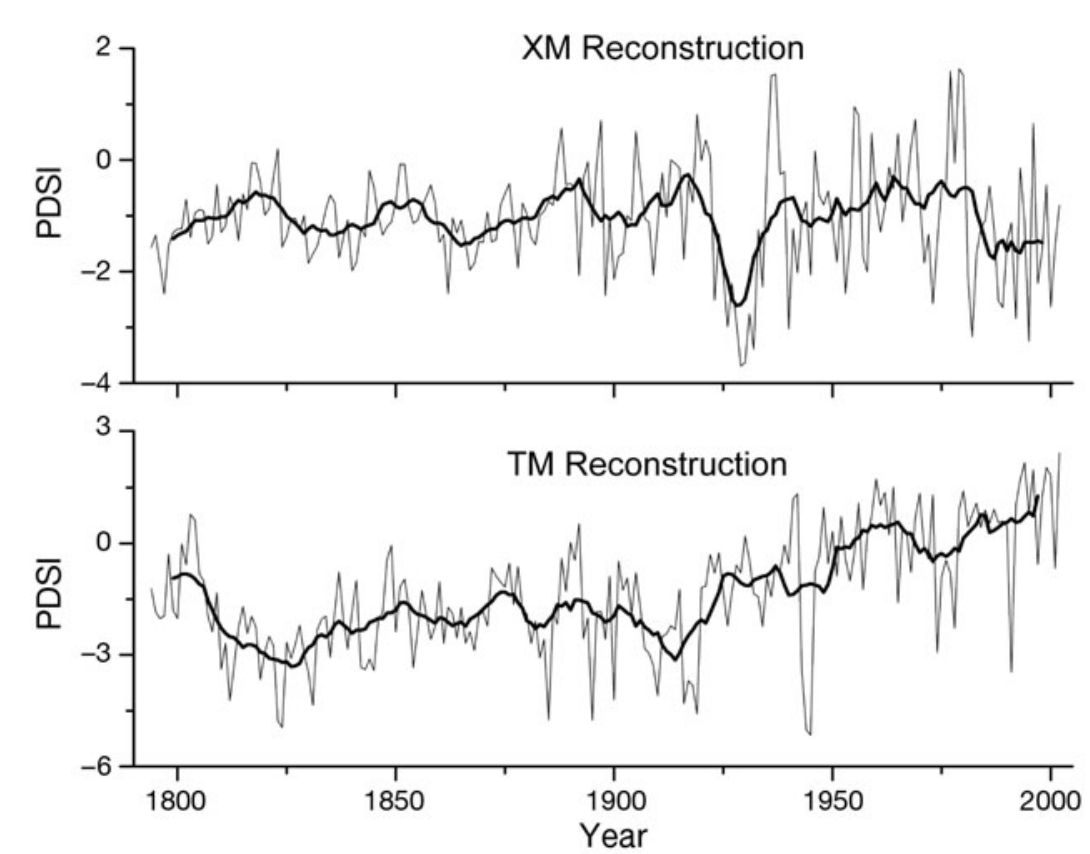

Fig. 7. Comparisons between Xinglong Mountain PDSI reconstructions (XM reconstruction) and Tianshan Mountain PDSI reconstruction (TM reconstruction). Both the annual (thin line) and the $11 \mathrm{yr}$ running average (thick line) values of the reconstructed PDSI data are shown for the interval from 1794 to 2003 
2008). Since the $1980 \mathrm{~s}$, a clear tendency towards a more arid climate has prevailed in eastern NW China, which is contrary to the moisturizing trend in western NW China (Shi et al. 2007). The comparison between Tianshen Mountain (TM) PDSI reconstruction (Li et al. 2006) and XM PDSI reconstruction in western and eastern NW China, respectively, suggests that the drought variations between these 2 regions have been inconsistent over the past 2 centuries (Fig. 7). For example, the 1820 s were the driest years in the TM reconstruction ( $\mathrm{Li}$ et al. 2006), while this period was relatively wet in eastern NW China according to the $\mathrm{XM}$ reconstructions. The driest epoch in the XM reconstruction was during the period from 1922 to 1934, with its driest year in 1929. The reconstructed megadroughts during the 1920 s to 1930 s are in agreement with results of other studies of eastern NW China (Liu et al. 2005, Li et al. 2007), while this is not the case for the TM reconstruction (Li et al. 2006).

Modeling results suggested that the water vapor in NW China originates from the Arabian Sea, the Bay of Bengal and the South China Sea, through advection by the Asian monsoon, as well as being influenced by extratropical circulation modes (Böhner 2006, Shi et al. 2007). The northward-moving Asian tropical monsoon currents are split into eastern and western branches by the Tibetan Plateau and influence the moisture conditions of eastern and western NW China, respectively (Yu et al. 2003, Böhner 2006). Since the 1980s, the strengthening (weakening) of the western (eastern) monsoon branch may have caused the moisturizing (drying) trends in western (eastern) NW China (Yu et al. 2003). Since drought variability in NW China has a strong connection with the variability of these tropical monsoon currents, the comparison between TM and $\mathrm{XM}$ reconstructions might also suggest that the variability of these 2 branches of tropical monsoon currents may be inconsistent for a long period during the reconstruction (Fig. 7). However, we stress that the sparse number of PDSI reconstructed grids between eastern and western NW China are insufficient for such comparisons, suggesting the need to develop PDSI reconstructions with better spatial coverage in NW China.

\section{CONCLUSIONS}

A XM PDSI reconstruction from 1794 to 2003 is presented for the eastern part of NW China, where few PDSI reconstructions are available. Following standard dendroclimatological methods, we developed a rigorous composite ring-width chronology for Xinglong Mountain. The tree-ring indices correlated well with the PDSI data, and thus were used to reconstruct the annual PDSI data over the past 2 centuries. Following the significant drought jump in 1921, the most extreme drought epoch from 1922 to 1934 was identified in our PDSI reconstruction. The drought epoch during the 1920 s to 1930 s was widespread in North China. Spectral analysis detected significant cycles that were possibly related to ENSO activity, the tropical biennial oscillation and solar influences. Compared to a significant moisturizing trend in western NW China, as identified by the TM reconstruction, XM reconstruction in eastern NW China showed an inconsistent pattern over the length of the reconstruction period. This discrepancy might indicate that the different moisture patterns between western and eastern NW China have existed for the last 2 centuries. Based on the relationships between the droughts in NW China and the tropical Asian monsoon, the drought histories in NW China might also indicate a change in the strength of the western and eastern branches of the northwardmoving tropical Asian monsoon. However, our preliminary research is only based on a few available PDSI reconstructions in NW China. Future studies using the PDSI datasets of longer time spans and larger areas of spatial coverage are needed in order to better understand regional drought regimes and their forcing mechanisms.

Acknowledgements. This research was supported by the National Basic Research Program of China (973 Program) (2009CB421306), the NSFC Innovation Team Project (40721061), the National Science Foundation of China (40671191 and 90502008) and the Program for New Century Excellent Talents in University (NCET-05-0888). The authors thank 3 anonymous reviewers and Edward R. Cook for their constructive comments and suggestions. The kind help of Annie Gerard for improving the language was highly appreciated. This is Lamont-Doherty Earth Observatory Contribution 7233.

\section{LITERATURE CITED}

Allan HL, Lindesay J, Parker D (1996) El Niño/Southern Oscillation and climate variability. CSIRO Publishing, Collingwood

Böhner J (2006) General climatic controls and topoclimatic variations in central and high Asia. Boreas 35:279-295

Chinese Committee of Agricultural Resources Planning (1984) Chinese natural resources planning summary. Science Press, Beijing (in Chinese)

Cook ER (1985) A time-series analysis approach to tree-ring standardization. PhD dissertation, The University of Arizona, Tucson, AZ

Cook ER, Meko DM, Stahle DW, Cleaveland MK (1999) Drought reconstructions for the continental United States. J Clim 12:1145-1162

- Dai AG, Trenberth KE, Qian T (2004) A global dataset of Palmer drought severity index for 1870-2002: relationship with soil moisture and effects of surface warming. J Hydrometeorol 5:1117-1130

Fritts HC (1976) Tree ring and climate. Academic Press, London 
Fu C, Wang Q (1991) The abrupt change phenomena of the southern Asian monsoon secular variation and its synchronization with global warming. Sci China B 6:666-672 (in Chinese)

Garfin GM, Hughes MK, Yu L, Burns JM, Touchan R, Leavitt SW, An ZS (2005) Exploratory temperature and precipitation reconstructions from the Qinling Mountains, northcentral China. Tree-Ring Res 61:59-72

Gou X, Chen F, Yang M, Li J (2005) Climatic response of treering width at different elevations over Qilian Mountains, northwestern China. J Arid Environ 61:513-524

Gou X, Chen F, Cook E, Jacoby GC, Yang M, Li J (2007) Streamflow variations of the Yellow River over the past 593 years in western China reconstructed from tree rings. Water Resour Res 43:W06434， doi:10.1029/2006WR005705

Holmes RL (1983) Computer-assisted quality control in treering dating and measurement. Tree-Ring Bull 43:69-95

> Li J, Gou X, Cook ER, Chen F (2006) Tree-ring based drought reconstruction for the central Tien Shan area, Northwest China. Geophys Res Lett 33:L07715, doi:10.1029/2006GL 025803

Li J, Chen F, Cook ER, Gou X, Zhang Y (2007) Drought reconstruction for north central China from tree rings: the value of the Palmer drought severity index. Int J Climatol 27: 903-909

Liang EY, Shao XM, Liu HY, Eckstein D (2007) Tree-ring based PDSI reconstruction since AD 1842 in the Ortindag Sand Land, east Inner Mongolia. Chin Sci Bull 52: 2715-2721

Liu Y, Cai Q, Shi J, Hughes MK and others (2005) Seasonal precipitation in the south-central Helan Mountain region, China, reconstructed from tree-ring width for the past 224 years. Can J Res 35:2403-2412

Lu R (2005) Interannual variation of north China rainfall in rainy season and SSTs in equatorial eastern Pacific. Chin Sci Bull 50:2069-2073

Mann HB (1945) Non parametric tests against trend. Econometrica 13:245-259

Mann ME, Lee JM (1996) Robust estimation of background noise and signal detection in climatic time series. Clim Change 33:409-445

May W, Bengston L (1998) The signature of ENSO in the

Editorial responsibility: Mauricio Lima,

Santiago, Chile
Northern Hemisphere midlatitude seasonal mean flow and high-frequency intraseasonal variability. Meteorol Atmos Phys 69:81-100

> Meehl GA (1987) The annual cycle and interannual variability in the tropical Pacific and Indian Ocean region. Mon Weather Rev 115:27-50

Meko DM, Graybill DA (1995) Tree-ring reconstruction of Upper Gila River discharge. Water Resour Bull 31: 605-616

Palmer WC (1965) Meteorological drought. Weather Bureau Res Paper 45, US Department of Commerce, Washington, DC

Qian WH, Qin A (2008) Precipitation division and climate shift in China from 1960 to 2000. Theor Appl Climatol 93:1-17

Shanxi Committee of Natural Disasters Annals (2002) Historical natural disasters annals. Chinese Meteorological Press, Beijing (in Chinese)

Shao XM, Huang L, Liu HB, Liang EY, Fang XQ, Wang LL (2005) Reconstruction of precipitation variation from tree rings in recent 1000 years in Delingha, Qinghai. Sci China Ser D 48:939-949

Shi Y, Shen Y, Kang E, Li D, Ding Y, Zhang G, Hu R (2007) Recent and future climate change in northwest China. Clim Change 80:379-393

Stokes MA, Smiley TL (1968) An introduction to tree ring dating. University of Chicago Press, Chicago, IL

Tian Q, Gou X, Zhang Y, Peng J, Chen T, Wang J (2007) Treebased drought reconstruction for the Qilian Mountains, northwestern China. Tree-Ring Res 63:27-36

Wigley TML, Briffa KR, Jones PD (1984) On the average value of correlated time series, with applications in dendroclimatology and hydrometeorology. J Clim Appl Meteorol 23:201-213

Wilhite DA (2000) Drought as a natural hazard: concepts and definitions. In: Wilhite DA (ed) Droughts: a global assessment. Routledge, London, p 3-18

Yang M, Yao T, He Y, Thompson LG (2000) The ENSO events recorded in the Guliya ice core. Clim Change 47:401-409

Yu Y, Wang J, Li Q (2003) Spatial and temporal distribution of water vapor and its variation trend in atmosphere over northwest China. J Glaciol Geocryol 25:149-156 (in Chinese)

Submitted: July 9, 2008; Accepted: October 17, 2008

Proofs received from author(s): January 15, 2009 